\title{
Los tópicos femeninos en Un hombre que se parecía a Orestes, de Álvaro Cunqueiro
}

\author{
Marta Mariño Mexuto \\ Universidade de Santiago de Compostela \\ mmarinom@gmail.com
}

https://dx.doi.org.10.12795/futhark.2020.il5.09

Fecha de recepción: II.01.2020

Fecha de aceptación: 20.03.2020

Resumen: Álvaro Cunqueiro, en su novela ganadora del Premio Nadal, Un hombre que se parecía a Orestes (1969), recrea el mito griego de Orestes de forma peculiar e innovadora. Introduce algunos personajes nuevos y modifica sustancialmente las características de los ya existentes en la tradición clásica. En el presente trabajo se analiza el tratamiento que el escritor mindoniense da a los cuatro principales personajes femeninos y cómo estos acaban correspondiéndose con tópicos literarios ampliamente conocidos. A pesar de que es innegable que los personajes femeninos cunqueirianos carecen a menudo de la profundidad de sus compañeros masculinos, los tópicos responden en este caso no tanto a una simplificación, como al gusto del autor por el constante juego de referencias literarias de todos los tipos y épocas.

Palabras clave: Tópicos, Personajes femeninos, Mito, Metaliteratura, Transformación.

\section{Feminine Topoi in Álvaro Cunqueiro's Un hombre que se parecía a Orestes}

Abstract: Álvaro Cunqueiro, in his novel Un hombre que se parecía a Orestes (1969), which granted him the Premio Nadal, recreates the Greek myth of Orestes in a peculiar and innovative way. He introduces some new characters and substantially changes the traits of the already existing ones in the classic tradition. In this work we will analyse the author's treatment of the four main female characters and how these end up fitting into well-known literary topoi. Although it is undeniable that female characters in Cunqueiro's novels often lack the depth of 
their masculine counterparts, topoi in this case do not respond to a simplification, but rather to the writer's liking for the constant game of literary references of ever kind and period.

Keywords: Topoi, Female characters, Myth, Metaliterature, Transformation.

Sumario: I. Categorización de los personajes femeninos en Cunqueiro. 2. Los personajes femenios en Un hombre que se parecía a Orestes. 2.I. Electra. 2.2. Ifigenia. 2.3. Doña Inés. 2.4. Clitemnestra. Conclusiones

\section{Categorización de los personajes femeninos en Cunqueiro}

En la novela Un hombre que se parecía a Orestes, de Álvaro Cunqueiro, vemos cómo cuatro de sus personajes femeninos (Electra, Ifigenia, Clitemnestra y doña Inés), parecen corresponderse en gran medida con tópicos; algunos de ellos, con una amplia tradición literaria. Sin embargo, en contra de lo que podría pensarse, estos personajes no se limitan a aparecer en la novela simplemente como encarnaciones de los distintos tópicos, sino que, a menudo, son conscientes de esa condición: Doña Inés e Ifigenia, en concreto, son conocedoras de su carácter metaliterario, lo que las hace especialmente interesantes, ya que sus acciones se ven condicionadas por el desarrollo de la obra y por las expectativas creadas sobre ellas. Así, descubrimos que Cunqueiro, lejos de presentarnos sin más un escenario plagado de tópicos, juega con los mismos y hace que sus personajes femeninos (al igual que los masculinos en muchos casos) sean conscientes de la tradición que contribuyó a su existencia.

En primer lugar, es necesario admitir que los personajes femeninos no suelen jugar un papel fundamental en las novelas de Cunqueiro, como ya ha sido advertido por la crítica en general. Así lo señala A. Pociña, en palabras de M. X. Nogueira:

A ausencia de protagonistas femininos na narrativa de Cunqueiro chamou a atención de Andrés Pociña, quen contrastou este feito co tratamento recibido polos heroes destas. Neste sentido, observou que "resulta verdadeiramente chamativo o feito de que, a carón de sete heroes, rebulan unha serie de mulleres case sempre intranscendentes, mesmo aquelas das que cabería esperar un tratamento máis coidado por parte de Cunqueiro" (cit. en Nogueira Pereira 2009: 35).

Incluso resulta sencillo hacer una clasificación de dichos personajes en unas pocas categorías, y casi todos pueden inscribirse en una u otra sin mayor dificultad; así ocurre con la clasificación llevada a cabo por Simona Geroldi, que se reproduce a continuación:

- Mundo clásico (belleza de estatua, solemnidad, prendas escuetas y lineales, sonrisa); 
- Mundo cortés (piel blanca, ojos claros, cintura y cuello sutiles, pecho abundante, lejanía, estado de casada, debilidad y juventud);

- Mundo romántico (fragilidad emotiva, ingenuidad, espíritu de sacrificio, devoción, aptitud al desmayo y al llanto);

- Mundo bíblico (la Virgen y las santas);

- Entorno gallego (fuerza corporal. "piernas gruesas, redondos tobillos de las mujeres de las tierras llanas, largos los brazos como de hijas de segador, arqueadas cejas bien pobladas", habilidad en hacer dulces y confituras de membrillo y comidas en general). (Geroldi 1997: 267)

Como veremos, las mujeres de Un hombre que se parecía a Orestes tampoco escapan a esta clasificación, pero, aun así, su estudio resulta de interés por el cruce de referencias literarias del que son resultado y, como se mencionó anteriormente, su propia conciencia, en algunos casos, de ser personajes ficticios. A continuación, se analizarán estos cuatro personajes para saber cómo se corresponden, total o parcialmente, con distintos personajes literarios femeninos que ya se han convertido en tópicos.

\section{Los personajes femeninos de Un hombre que se parecía a Orestes}

\section{I. Electra}

Electra e Ifigenia constituyen dos tipos de mujer opuestos, tanto desde el punto de vista físico como psicológico, que ya encontramos en las tragedias clásicas que tratan el tema de Orestes e incluso en las pertenecientes a otros ciclos, como la pareja Antígona-Ismene en la Antígona de Sófocles. Se nos describen exteriormente de forma contrapuesta: "Así como Electra era pequeña y morena, Ifigenia era alta y rubia, y en la blanca piel salía a su madre” (Cunqueiro 1987: 219). Y, mientras que Ifigenia no envejece, el cuerpo de Electra acusa el paso del tiempo:

Y aun parecía que el que Ifigenia no envejeciese, que era el precio de las súbitas arrugas que a Electra le surgían en la frente y en las comisuras de los labios, e imaginaba que envejeciendo Ifigenia, ella remozaría, y volvería a la piel de los quince años, a los pechos levantados y tan redondos, a la cintura estrecha, al vientre plano y a los delgados tobillos. (Cunqueiro 1987: 216)

Ifigenia, encerrada en una torre como una etérea princesa esperando la llegada del príncipe (en este caso, su hermano), contrasta con la Electra exiliada que, siempre preparando la venganza, acaba como criada en Tebas en casa de un fundidor de dientes, cuidando a los hijos y a la esposa loca del mismo. En tanto que trabajadora, podría inscribirse dentro de las mujeres pertenecientes al entorno gallego, según la clasificación de Geroldi. Aunque no se corresponda plenamente con este apartado, está claro que no encaja en ninguno de los demás. En la Electra 
de Eurípides, la protagonista también se ve abocada a una vida muy humilde, casada con un labrador, y su situación es igualmente descrita de forma realista.

Electra cumple la función de instigar constantemente a Orestes a realizar el matricidio, hasta el punto de que llega a ser lo único que le impide a este llevar la vida que querría, lejos de sus obligaciones de héroe trágico:

[...] y ya se veía [Orestes] en una conversación con Egisto en una solana, el cual le ofrecía su amistad y dinero, un viaje por las antípodas y una joven esposa [...]. Pero despertó sobresaltado, porque por una de las puertas del sueño había entrado sigilosamente Electra y lo contemplaba iracunda. (Cunqueirol987: I5I)

La determinación de Electra llega casi hasta la locura: toda su vida está, como la de Orestes, encaminada a la venganza, pero ella no manifiesta dudas ni se aparta de su objetivo, al contrario que su hermano. El propio Cunqueiro admitía que "si Orestes consigue llegar en mi novela a la ciudad de su niñez es por el empuje de su hermana; él jamás lo hubiera conseguido" (Nicolás, 1994: 126). No es, por tanto, casual el hecho de que se nos describa con trazos masculinos. La dureza de Electra se atenúa sólo en el trato que le da a su hermano, que es ciertamente maternal:

Era la primera noche que Orestes iba a pasar lejos de Electra. Cuando Orestes estaba en cama y ya se le acercaba el sueño, Electra venía silenciosa y solícita, le arropaba, le tocaba los pies por si los tenía fríos, le frotaba la frente con las yemas de los dedos mojadas en aceite perfumado para que tuviera sueños felices, y se marchaba de puntillas, presurosa. (Cunqueiro 1987: 147)

Es bastante habitual que los personajes femeninos de las obras cunqueirianas, al mismo tiempo que mantienen una relación amorosa con el protagonista, desarrollen hacia éste comportamientos maternales. Como una madre, Electra cuida a su hermano', pero también se muestra inflexible en lo que atañe al cumplimiento de los deberes de él (la venganza, en este caso), y es tal su influencia sobre el joven que, como vimos anteriormente, irrumpe en sus sueños recordándole lo que tiene que hacer. No por casualidad aparece justamente cuando él sueña con casarse: por un lado, la boda le impediría el regreso a Micenas y, por otro, una posible relación incestuosa se insinúa varias veces a lo largo de la

I Otro rasgo maternal más se desprende del hecho de que le diga a Orestes exactamente las palabras que debe pronunciar y los gestos que debe realizar: "Tú [...] declararás siempre que eres Orestes, y que te diriges, sin perder hora, a cumplir la venganza. [...]. La cabeza levantada, el manto desgarrado por las zarzas de los caminos, los zapatos cubiertos de polvo. Pides agua, bebes, te mojas los ojos y das las gracias" (Cunqueiro 1987: I46). 
novela ${ }^{2}$ (presentada siempre como rumor), como ya sucedía en varios autores antiguos.

\section{2. Ifigenia}

Ifigenia es un personaje completamente supeditado a las reglas de la tragedia, esa tragedia pendiente de la venganza para ser escrita, pero que todos parecen tener presente en el reino de Micenas. De hecho, se mantiene con vida y en una perpetua juventud (con "la dulce belleza de sus dieciséis años, con el cabello recogido en dos trenzas y la redonda pantorrilla realzada por el zapato de medio tacón” [Cunqueiro 1987: 219]), en tanto que resulta útil a la tragedia. Aun así, su papel en la misma no pasaría de ser meramente decorativo:

Ifigenia moza es necesaria para la venganza. Tanto como la espada del infante vengador [...]. Y el que no envejezca Ifigenia es una probabilidad mayor de que la venganza pueda llegar repentina, el día menos pensado. Probablemente, aunque Ifigenia quisiese no podría envejecer. (Cunqueiro 1987: 38)

Pero no podían [los espejos] devorarla mientras Orestes viviese, porque Ifigenia tenía que estar encendiendo las luces en la escena de la venganza [...]. (Cunqueiro 1987: 220)

Resulta curioso el hecho de que, en vez de Electra, como en las versiones tradicionales, sea Ifigenia la responsable de reconocer a su hermano cuando vuelva para vengarse. Además, en la novela de Cunqueiro no encontramos ningún indicio de que Ifigenia haya sido sacrificada por su padre, Agamenón (el tema principal de Ifigenia en Áulide e Ifigenia en Táuride, de Eurípides), o haya estado a punto de serlo, sino que, más bien, Ifigenia desempeña aquí un papel similar a Crisotemis, una tercera hermana presente en la fábula original y que no aparece en la novela. Aquí, son Electra e Ifigenia los personajes entre los que se establece una oposición similar a la de Antígona e Ismene, pero, en la tragedia sofoclea, al hallarse ausente Ifigenia, era Crisotemis la que desempeñaba su papel:

In Sophocles' extant dramas, the Antigone-Ismene pairing has its precise counterpart in Electra-Chrysothemis. Sophocles resorts twice to the same asymmetry of sisterhood and conflict. Reflecting on George Eliot's Adam Bede, Freud suggests that the contrastive intimacy between the small dark and the taller fair-haired young women in the house hold stands for a primal symbolic dissociations between fundamental tenets in the feminine psyche or, rather, in this psyche as imagined and represented by men. Chrysothemis, of course, means the 'lit' or 'golden' one. (Steiner 1984: 145)

\footnotetext{
${ }^{2}$ Valga de ejemplo el siguiente pasaje: "Pero Filón el Mozo, que es la autoridad a quien hay que seguir en el personaje Electra, escribió una escena en la que pretendía dejar al descubierto el motivo de haberse metido en la cama de Orestes, y fue para, llegada el alba, descubrirse y decirle que aquel pecado era uno más a sumar en la cuenta de Egisto [...]" (Cunqueiro 1987: 218).
} 
Por otro lado, Massimilla Pialorsi (2013: 493) señala que el cautiverio de Ifigenia en una torre es "una evocación de los mitos de Dánae y de la leyenda de Santa Bárbara" ${ }^{3}$. Ciertamente, Ifigenia se muestra como una mujer más soñada que real, distinta en todo a su hermana, de apariencia delicada y casi incorpórea hasta el punto de que "con el paso de los años, Ifigenia se iba haciendo luminosa, y bajo la transparente y blanquísima piel se adivinaban los delicados huesos" (Cunqueiro 1987: 219). Muere finalmente, según una de las múltiples versiones ${ }^{4}$, devorada por los espejos de la torre:

Se consolaba con la amistad que creía que le tenían los espejos, pero los espejos de la sala, grandes ojos redondos en las paredes, la devoraban. Filón el Mozo le explicó a Eumón el tracio que Ifigenia solamente se alimentaba de aire y de sueño, y que los espejos, viéndose perecer en la penumbra de la sala, vampiros al fin, acordaron devorar a la infanta, que ya no era más que una sonrisa como un rayo de luz. (Cunqueiro 1987: 220)

Egisto se aprovecha de los tópicos sobre las personalidades de las hermanas para justificar el enclaustramiento de Ifigenia:

Egisto explicaba el encierro de Ifigenia con un sueño que había tenido, que aparecía Electra con unas uñas enormes y desgarraba el rostro de su hermana, y se llevaba su mano derecha para llamador de una puerta, decía Electra huyendo. Y Egisto aseguraba que salvaba a Ifigenia de las iras de la terrible Electra. (Cunqueiro 1987: 219)

A pesar de que Electra nunca muestra una conducta violenta en la novela, y mucho menos hacia su hermana, de la que se halla separada durante toda la acción, parece tener fama de ser temible y colérica hasta el punto de que sea necesario poner a Ifigenia fuera de su alcance y de que esta historia resulte creíble.

Ifigenia muestra características de varios de los "mundos" femeninos que establece Simona Geroldi. Por un lado, pertenecería, por ámbito cultural, al mundo clásico, y su belleza de estatua y permanente sonrisa la relacionan con este. Asimismo, su papel decorativo en la tragedia la semeja aún más a una estatua. Pero también su delicadeza de princesa de cuento de hadas y sus rasgos físicos la acercan al mundo cortés, a pesar de no cumplir el requisito de estar casada (aunque su encierro en la torre la hace igualmente inaccesible en ese sentido).

\footnotetext{
${ }^{3}$ Aunque es muy probable que Cunqueiro tuviese presente la historia de Dánae, la imagen de la princesa - doncella recluida en una torre esperando su liberación también aparece constantemente en numerosos cuentos de hadas, como en Rapunzel, de los hermanos Grimm.

${ }^{4}$ El narrador, que interviene en la novela en varias ocasiones comentando la acción, señala que prefiere esta versión de la muerte o desaparición de Ifigenia a otras más prosaicas que también menciona, como incluso que fuese envenenada por su hermana (cf. Cunqueiro 1987: 22I)
} 
Ambas hermanas se definen, como hemos ido viendo, por oposición con respecto a la otra: todo lo que la primera tiene de determinación y fortaleza es en la otra fragilidad y pasividad.

\section{3. Doña Inés}

Doña Inés, protagonista de la pieza teatral $A$ noite vai coma un rí $0^{5}$, vive rodeada de sus fantasías sentimentales, esperando el amor que nunca llega, al igual que Egisto espera que Orestes le dé muerte: ella vive a la expectativa del desenlace de una novela sentimental y él, de una tragedia. Incluso su descripción física responde a la idealización de una heroína romántica, y sus apariciones y gestos son completamente teatrales, tanto cuando se convierte en un personaje de los pasos teatrales escritos por Filón el Mozo, como en el resto de la novela:

DOÑA INÉS asoma en la baranda del primer piso. Parece que encendiesen una luz allá arriba. Trae el rubio cabello suelto por la espalda, y una rosa blanca en la mano derecha. (Cunqueiro 1987: 175)

Camiño Noia, aunque refiriéndose exclusivamente a la pieza $A$ noite vai coma un río, pone de manifiesto el conflicto en el que vive doña Inés, no sólo entre idealismo y realidad, sino entre "un amor imaxinario (espiritual) fronte ó amor carnal (paixonal)". Además, Cunqueiro

vai máis aló e quere suscitar debate poñendo na súa boca a concepción aristotélica da división entre corpo e alma, que recolle e reelabora Santo Tomás converténdose en dogma de fe para os católicos. [...]. Un debate amorsexo que el sitúa no de idealismo-realidade. Dona Inés fala como crente católica, quere amar un home pero teme a relación sexual por ser pecaminosa. (Noia Campos 2017: 119)

La crítica ha relacionado en numerosas ocasiones a doña Inés con el personaje del mismo nombre que protagoniza la novela Doña Inés (Historia de amor), de Azorín, publicada en 1925. No obstante, no parece que las semejanzas entre ambas mujeres sean suficientes como para justificar esta relación. En efecto, las dos viven comprometidas historias de amor, pero el vínculo es muy tenue. La descripción física que se hace de ellas en las dos novelas es radicalmente distinta y, aunque no se trate de un hecho determinante, ya que evidentemente puede haber sido intencionalmente alterado por Cunqueiro, este tenía muy en cuenta la apariencia externa como determinante de un tipo u otro de mujer. En la obra de Azorín, leemos:

\footnotetext{
${ }^{5}$ Originalmente en gallego, fue escrita varios años antes de Un hombre que se parecía a Orestes, en 1960 , como una pieza independiente, a diferencia de otras que ya se concibieron para ser insertadas en una novela.
} 
La cara de la desconocida es morena. En lo atezado del rostro, resalta el rojo de los labios. Entre lo rojo de los labios - al sonreír, al hablar- blanquea la nitidez de los menudos dientes. El pelo negro se concierta en dos rodetes a los lados de la cabeza. Una recta crencha divide la negra cabellera. [...] Amplia mantilla negra arreboza la cara y cae por el busto hasta el brazo desnudo que, puesto de través, la sostiene a la altura del seno. (Azorín 1973: 72-73)

No sólo el color del pelo cambia, sino que la impresión general es totalmente distinta: se pasa de la rubia heroína romántica que sostiene una rosa blanca, a una mujer mucho más real, de cabello y mantilla negras, como acabamos de apreciar en fragmentos de ambos autores.

Hay muchos más motivos para relacionar a doña Inés con su homónima en la materia de Don Juan, empezando por el hecho de que se trate en ambos casos de personajes teatrales: para Inmaculada López Silva, "Dona Inés, en A noite vai coma un río, non é máis ca un desorientado personaxe que quedou desenganchado do Don Juan" (201 I: 644). Aunque la Inés de Cunqueiro aparezca también en las partes narrativas de la novela, donde cobra verdadero protagonismo es en los pasos teatrales que se incluyen dentro de la misma. No se trata de un hecho baladí, ya que doña Inés es un personaje más consciente que otros de su carácter ficticio y estrechamente ligado al teatro. Massimilla Pialorsi señala acertadamente que

[...] la dama reconociéndose ente lingüístico se eleva como prototipo "positivo" de la discontinuidad irónica del hombre moderno, que no se rinde como Orestes o Egisto, sino que hace alarde de su condición de ser ficticio e interpreta lo mejor que puede su papel soñado por él mismo y por el autor supremo. (Pialorsi 2013: 497).

Robert Spires también opone doña Inés al resto de los personajes, incapaces de reconocer su condición ficticia:

Because of her role as intruder along with her self-awareness of her linguisticartistic ontology, Doña Inés represents the realization of a rebellion the other characters are unwilling to attempt. (Spires 1984: 342)

Acudiendo ahora al Don Juan de Zorrilla, algo que lo acerca a la doña Inés cunqueiriana es el paralelismo a la inversa que se produce entre estas dos obras: mientras que Don Juan mantiene relaciones con incontables mujeres sin enamorarse de ninguna, la doña Inés de Un hombre que se parecía a Orestes se enamora locamente de distintos transeúntes que pasan por el Vado de la Torre, pero todas estas historias acaban de forma dramática, pues no se corresponden con sus ideales amorosos.

Creemos que la única en señalar una posible relación con Inés de Castro fue Ana Sofía Pérez-Bustamante (1990: 199), pero, desafortunadamente, no da más datos al respecto. No obstante, es muy probable que Cunqueiro también tuviera en 
mente este personaje a la hora de configurar su doña Inés. Es conocido su interés por la Galicia medieval ${ }^{6}$ e Inés de Castro, gallega y amante (y esposa póstuma) del rey Pedro de Portugal, reúne muchas de las características que atraían al autor mindoniense, aparte, por supuesto, de ser la protagonista de una trágica historia de amor. Sabemos por varios de sus artículos periodísticos que sus fuentes eran la Crónica do Rei don Pedro, de Fernâo Lopes, las tragedias La reine morte (1942), de Henry de Montherlant y Reinar después de morir, de Vélez de Guevara, que constituye el principal testimonio sobre este tema en la literatura castellana. Por supuesto, conocía el Canto III de Os Lusíadas $^{7}$ y, seguramente, estaría también familiarizado con las Trovas á morte de Inés de Castro, de García de Resende o el drama Inez de Castro de Victor Hugo.

Siempre según la clasificación de Geroldi, doña Inés puede encuadrarse entre el mundo romántico y el mundo cortés, aunque inclinándose más hacia este último. La región del Vado de la Torre, de la que Inés es soberana, apenas muestra características del mundo clásico (que sí se encuentran en otros ambientes reflejados en la novela), sino que parece sacado de una novela de caballerías. Aunque el personaje no cumple el requisito de estar casada, sí lo hace con los demás. En cuanto al mundo romántico, doña Inés parece identificarse con las actitudes mencionadas, pero no encaja plenamente en ellas, porque, en la novela, es Clitemnestra quien lo hace, aunque de una forma un tanto exagerada, que roza lo paródico. Así, mientras que nada en la caracterización de doña Inés parece ridiculizarla (aunque su situación pueda tener tintes cómicos), sí sucede con la de Clitemnestra, que representa de forma menos benévola esa fragilidad emotiva, ingenuidad y tendencia al desmayo características del mundo romántico, pues, cada vez que se la describe, queda patente su escasa inteligencia.

\section{4. Clitemnestra}

Lejos de la imagen que nos ofrecen de ella tanto Esquilo como Eurípides (el último es más benevolente, pero no disimula su culpabilidad en el asesinato de Agamenón), la amante de Egisto aparece descrita en la novela con adjetivos como "bobalicona y sensible", incapaz de entender la situación en la que se ve envuelta:

\footnotetext{
${ }^{6}$ Cunqueiro es uno de los representantes del 'neotrobadorismo' en la poesía gallega, junto con Fermín Bouza Brey, especialmente con su obra Cantiga nova que se chama ribeira (1933).

${ }^{7}$ Xosé Filgueira Valverde fue autor de la biografía Camôens (1993) que, aunque publicada tras la muerte de su amigo personal, Cunqueiro, nos habla del interés por parte del círculo cercano de este último, hacia el principal representante de la épica portuguesa.

${ }^{8}$ Más respetuoso que el narrador, Eumón de Tracia, amigo de Egisto, se refiere a la reina como "la blanda Clitemnestra" (Cunqueiro 1987: 98).
} 
Clitemnestra, bobalicona y sensible, no comprendía cómo le daban a ella aquellos sustos, y por qué su hijo Orestes iba a aparecer una noche de truenos a dar muerte a su Egisto, y que mejor hubiese sido que el infante permaneciera en la casa, cobrando las rentas, guardando las ovejas, ayudando a mantener el gobierno real, y casándose con una rica que sacase a aquella familia de aprietos. Clitemnestra con lo que mejor soñaba, recostada en su sillón, era con cisnes blancos y con bolas de cristal, de colores. (Cunqueiro 1987: 214)

Era en el razonar confusa, en el hablar voluble, y nunca sabía terminar su historia; le salían ramas a cada párrafo, y por ellas se iba poco menos que gorjeando, que su decir era una mezcla de grititos, risas, suspiros, confidencias, lágrimas, voces de mando, citar con sus abuelos y mucho "iya lo decía yo!", y estando en la mejor animación, de pronto callaba y se quedaba mirando para el techo, como si viese volar mariposas, con la boca entreabierta y la cabeza ladeada. (Cunqueiro 1987: II4-II5)

Claramente perteneciente al tipo que Simona Geroldi denomina "mundo romántico", Clitemnestra muestra rasgos en común con otra célebre adúltera literaria: Emma Bovary. Se podrían hallar, quizás, motivos para relacionarla con otros personajes como Ana Ozores o Ana Karénina, pero creemos que Emma es quien mejor encarna las características que hacen de ella el modelo de la novela de adulterio del siglo XIX; hasta el punto de inspirar el término "bovarismo". Si bien es cierto que no hay semejanzas en sus respectivas descripciones físicas, sí encontramos numerosos paralelismos. Como Madame Bovary, Clitemnestra busca consuelo en la literatura a lo mediocre de su existencia, en este caso, en las novelas sentimentales bizantinas que le leía el enano Solotetes:

A Clitemnestra le gustaría hacer una navegación como las que leía Solotetes, anclando el barco en una pequeña bahía una noche de luna llena. Le dificultaba ahora el embarque el elegir el traje que más la favorecería, y dudando entre uno blanco, de piqué, o una bata a rayas rojas y amarillas, regoldó, y se durmió [...]. (Cunqueiro 1987: 117)

Emma también contó con un personaje que la instruyó en la lectura de novelas sentimentales; en este caso, se trata de una mujer que hacía tareas domésticas en el convento donde fue educada de niña:

Elle contait des histoires, vous apprenait des nouvelles, faisait en ville vous commissions, et prêtait aux grandes, en cachette, quelque roman qu'elle avait toujours dans les poches de son tablier, et dont la bonne demoiselle ellemême avalait des longs chapitres, dans les intervalles de sa besogne. Ce n'étaient qu'amours, amants, amantes, dames persecutées s'évanouissant dans des pavillons solitaires, postillons qu'on tue à tous les relais, chevaux qu'on crêve à toutes les pages, forêts sombres, troubles du cœur, serments, sanglots, larmes et baisers, nacelles au clair de lune, rossignols dans les bosquets, messieurs braves comme des lions, doux comme des agneaux, vertueux 
comme on ne l'est pas, toujours bien mis, et qui pleurent comme des urnes. (Flaubert 1966: 72)

La alimentación de toda esta fantasía provoca que la joven Emma intente "savoir ce que l'on entendait au juste dans la vie par les mots de félicité, de passion et d'ivresse, qui lui avaient paru si beaux dans les livres" (Flaubert, 1966: 69).

La preocupación constante de Clitemnestra por su atuendo, que se describe varias veces a lo largo de Un hombre que se parecía a Orestes (a pesar de las estrecheces en las que viven), es compartida también por Madame Bovary. La reina de Micenas, influenciada por las lecturas, desea desempeñar un papel trágico en el que se vea favorecida, y busca teatralizar su sufrimiento:

Aun la angustia cósmica de la Clitemnestra trágica se ha transformado en melodrama patético: "Y recordando a Solotetes se echó a llorar, mientras alcanzaba un espejo de mano, que no lloraba bien si no tenía el mirador delante" (p.I l6). La tristeza no se debe a su destino trágico, sino al hecho de que el enano que le leía novelas alejandrinas ya está muerto (y sólo el espejo le permite sostener este papel teatral). Tal representación reduce a la Clitemnestra trágica de amante-madre desgraciada por fuerzas cósmicas, a pobre burguesa incapaz de sobreponerse a una existencia prosaica. (Spires 1978: 257)

Esta última afirmación de Spires podría aplicarse igualmente a Emma Bovary. La actitud de esta última tras la muerte de su madre resulta semejante en su afán de protagonizar un rol literario trágico, favorecido por la desgracia sobrevenida en la vida real:

Quand sa mère mourut, elle pleura beaucoup les premiers jours. [...] Emma fut intérieurement satisfaite de se sentir arrivée du premier coup à ce rare idéal des existences pâles, où ne parviennent jamais les cœurs médiocres. Elle se laissa donc glisser dans les méandres lamartiniens, écouta les harpes sur les lacsm tous les chants des cygnes mourants, toutes les chutes de feuilles, les vierges pures qui montent au ciel [...]. (Flaubert 1966: 73)

Por otra parte, el adulterio también representa un hecho clave en la Orestíada $\mathrm{y}$, aunque no tenga tanta importancia en Un hombre que se parecía a Orestes, constituye un vínculo con la novela francesa. Tanto Charles Bovary como el Egisto de Cunqueiro se presentan como hombres cobardes y mediocres que, incluso, son ridiculizados en algunas situaciones. Sin embargo, Clitemnestra no es consciente o no parecen preocuparle los defectos de su amante, quizás debido a su propia mediocridad.

Frente a la novela de Cunqueiro, en la Orestíada, el personaje de Clitemnestra muestra rasgos, como la decisión o la osadía, considerados casi exclusivamente masculinos en el contexto de la obra. Así sucede también en Agamenón, donde ella es la asesina y hace gala de un carácter más decidido que 
Egisto. La prisionera Casandra9 llega a gritar, refiriéndose a la reina: "iEsta leona de dos pies, que con un lobo se acuesta en ausencia del noble león, me va a matar!" (1986: 424). En cambio, en Un hombre que se parecía a Orestes, al contrario que Egisto, ella no siente una gran preocupación por la llegada de Orestes, ni remordimientos por la muerte de Agamenón o la unión con el usurpador, sino que parece, la mayor parte del tiempo, inmersa en sus fantasías $y$, ocasionalmente, preocupada por pequeños problemas domésticos.

\section{Conclusiones}

Los personajes femeninos de Cunqueiro, como hemos visto, se pueden identificar en la mayoría de las ocasiones con tipos de mujer determinados o tópicos, pero esto no les resta interés. Por un lado, algunos personajes surgen de un intrincado cruce de referencias literarias, que hemos tratado de simplificar en los casos de doña Inés y Clitemnestra, y que permiten a Cunqueiro llevar a cabo una experimentación lúdica, reflejo de su interés en distintas y muy variadas obras literarias. El autor utiliza fuentes como la tragedia griega y la tradición posterior, para, en algunos casos, subvertirlas y, en otros, llevar a cabo un peculiar homenaje. Por otro lado, es importante resaltar que Cunqueiro utiliza el aspecto físico como reflejo de la interioridad, de modo que, como se ve a partir de los apartados establecidos por Geroldi, la apariencia de una mujer se utiliza en la novela para determinar su personalidad y su papel. Además, estas descripciones externas funcionan por contraste, como en el caso de Electra e Ifigenia.

En cuanto al resultado de la comparación de estos personajes entre sí, evidentemente, el caso de las hermanas de Orestes resulta especialmente llamativo, porque encarnan los tópicos femeninos más opuestos entre sí, lo que resulta imprescindible para el efecto requerido en la novela. Clitemnestra resultaría igualmente una antagonista interesante con respecto a Electra, pero ambas nunca llegan a estar presentes simultáneamente en la acción. Ifigenia y su madre son quienes muestran más semejanzas en sus respectivos caracteres: un comportamiento a menudo infantil y un acusado sentimentalismo. Doña Inés, aunque también posee esta última característica, destaca por su especial consciencia de ser un ente literario, y su locura, lejos de resultar ridícula, alcanza más bien un efecto trágico.

Así pues, los tópicos femeninos de los que se sirve el autor mindoniense no son recursos que enmascaren su falta de originalidad. A pesar de que,

\footnotetext{
${ }^{9}$ Casandra, princesa troyana, fue traída a Micenas por Agamenón como botín tras la guerra de Troya, y este hecho suscitó la ira de su mujer legítima, Clitemnestra. Ninguno de estos sucesos se menciona en Un hombre que se parecía a Orestes.
} 
indudablemente, muchas veces ofrezca una visión simplista de la mujer, mediante los tópicos es capaz de llevar a cabo una continua experimentación e innovación literaria.

\section{Referencias bibliográficas}

CUNQUeIRO, A. (1989). Un hombre que se parecía a Orestes. Barcelona: Destino.

EsQUILO. (1986). Agamenón en Tragedias. Trad. de B. Perea Morales e intr. de M. Fernández Galiano. Madrid: Gredos, 373-440.

FlaUberT, G. (1966). Madame Bovary. Paris: Garnier-Flammarion.

GALLEGo, J. (2000). Figuras de la tiranía, lo femenino y lo masculino en la Orestía de Esquilo. Studia Historica. Historia Antigua, 18, 65-90.

GeROLDi, S. (I997). La duodécima mujer: pesquisa entre las figuras femeninas en la obra de Álvaro Cunqueiro a partir de la Balada de las damas del tiempo pasado. Actas do IV Congreso de Estudios Galegos (ed. Benigno Fernández Salgado). Oxford: Centro de Estudios Gallegos, II, 26-273.

LÓPEZ SILVA, I. (20II). Cunqueiro e a teatralidade, mitos e verdades. Mil e un cunqueiros. Novas olladas para un centenario. Santiago de Compostel: Consello da Cultura Galega, 623-653.

NicolÁs, R. (1994). Entrevistas con A. Cunqueiro. Vigo: Nigra.

Nogueira PereiRA, M. X. (2009). Soñadores e familia. Os personaxes na narrativa de Álvaro Cunqueiro. Santa Comba (A Coruña): tresCtres Editores.

NoIA CAMPOS, C. (2017). Figuras femininas na obra de Álvaro Cunqueiro. Entre o desexo e a negación. Madrygal. Revista de Estudios Gallegos, 20, I I3-126.

Pérez-Bustamante Mourier, A. S. (1990). Un hombre que se parecía a Orestes de Álvaro Cunqueiro: El replanteamiento moderno del mito y la tragedia. En Hernández Guerrero, J. A. (ed.). Teoría del arte y teoría de la literatura. Cádiz: Seminario de Teoría de la Literatura, 199-205.

PIALORSI, M. (20I3). Juegos metaliterarios e imaginación en la obra de Álvaro Cunqueiro, [en línea, ref.II-6-20I9]. Disponible en Web: https://eprints.ucm.es/23998/

SPIRES, R. C. (1978). La novela española de posguerra. Madrid: Editorial Planeta/Universidad de Kansas. 
